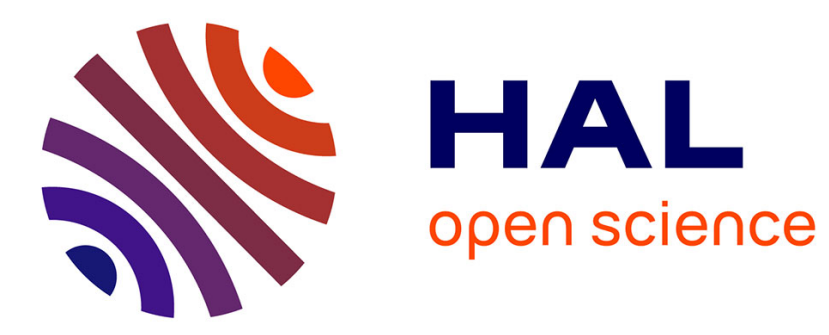

\title{
Ontogeny of food grasping in mouse lemurs: behavior, morphology and performance
}

\author{
G. Boulinguez-ambroise, P. Zablocki-thomas, F. Aujard, A. Herrel, E. \\ Pouydebat
}

\section{- To cite this version:}

G. Boulinguez-ambroise, P. Zablocki-thomas, F. Aujard, A. Herrel, E. Pouydebat. Ontogeny of food grasping in mouse lemurs: behavior, morphology and performance. Journal of Zoology, 2018, 308 (1), pp.1-8. 10.1111/jzo.12652 . hal-03031405

\section{HAL Id: hal-03031405 \\ https://hal.science/hal-03031405}

Submitted on 12 Jan 2021

HAL is a multi-disciplinary open access archive for the deposit and dissemination of scientific research documents, whether they are published or not. The documents may come from teaching and research institutions in France or abroad, or from public or private research centers.
L'archive ouverte pluridisciplinaire HAL, est destinée au dépôt et à la diffusion de documents scientifiques de niveau recherche, publiés ou non, émanant des établissements d'enseignement et de recherche français ou étrangers, des laboratoires publics ou privés. 


\title{
Ontogeny of food grasping in mouse lemurs: behavior, morphology and performance
}

\author{
G. Boulinguez-Ambroise (D), P. Zablocki-Thomas (D), F. Aujard, A. Herrel (iD \& E. Pouydebat (iD \\ UMR 7179- CNRS, National Museum of Natural History, Paris, France
}

\section{Keywords}

development; evolution; prehension; primates; Microcebus; grasping; limb morphology; ontogeny.

\section{Correspondence}

Grégoire Boulinguez-Ambroise, Department Adaptations du Vivant, UMR 7179 -CNRS/ MNHN, MECADEV Paris 75321, France.

Tel: +33 (0) 160479627

Email: gregoire.boulinguez-ambroise@cri-paris.org

Editor: Andrew Kitchener

Received 11 July 2018; revised 21 December 2018; accepted 3 January 2019

doi:10.1111/jzo.12652

\begin{abstract}
In primates, grasping constitutes a vital function involved in many behaviors. Anatomical specializations of the prehensile extremities originated early-on in their evolution. However, the precise functional and ecological contexts that have driven this evolution remain unclear. Interspecific comparative studies show that a given morphology can induce different grasping behaviors and also that a given behavior can be performed using different morphological structures. In this context, an intraspecific ontogenetic approach offers the opportunity to describe the relations between patterns in grasping behavior and patterns of grasping morphology. We quantified manual grasping strategies and the associated morphometric (i.e. segments lengths) and performance (i.e. pull strength) traits for both limbs during the development of a small arboreal primate, the gray mouse lemur (Microcebus muri$n u s$ ). Our results show an early onset of grasping in young mouse lemurs. Moreover, younger individuals had relative longer hindlimbs (i.e. tibia and metatarsus) allowing them to have near-maximal levels of grasping strength. This very fast development despite an incomplete neuromuscular development highlights the importance of this grasping function directly after birth.
\end{abstract}

\section{Introduction}

In primates, grasping constitutes a vital function involved in many behaviors including locomotion, postural behavior, food grasping and social interactions (Napier, 1956; Reghem et al., 2011; Sustaita et al., 2013; Völter, Rossano \& Call, 2015). When investigating the relations between grasping form and function, interspecific studies face the difficulty that a same morphology can induce different behaviors in different species, and a specific behavior can be the result of different morphologies in different species (Pouydebat, Gorce \& Bels, 2009). However, an intraspecific ontogenetic approach offers the opportunity to highlight the relations between patterns in grasping behavior and patterns of grasping morphology without these confounding effects. Indeed, recent ontogenetic studies have shown changes in locomotor behavior and substrate use during development. For example younger chimpanzees (Pan troglodytes), gorillas (Gorilla beringei beringei) and baboons (Papio anubis) display a wider locomotor repertoire, engage much more in vertical climbing, forelimb suspension and other arboreal behaviors than adults, which remain largely quadrupedal and spend more time on the ground (Doran, 1992, 1997; Sarringhaus, MacLatchy \& Mitani, 2014; Druelle, Young \& Berillon, 2017). Studies in baboons (Papio anubis), capuchin monkeys (Sapajus apella, Cebus albifrons), chimpanzees and rhesus monkeys (Macaca mulatta) have shown changes in the morphology of the hands and feet involving differences in bone proportions, size and robusticity (Young \& Heard-Booth, 2016; Druelle et al., 2017; Patel et al., 2018). The next step is thus to investigate whether these structural changes are associated with behavioral transitions by exploring the relations between grasping behavior and morphology (Druelle et al., 2017).

Moreover, ontogenetic studies provide the opportunity to investigate the ecological pressures that may constrain development in primates. As soon as they are born, infants grasp their mother when being carried in addition to grasping arboreal substrates (Colas, 1999; Nakamichi \& Yamada, 2009; Peckre et al., 2016). Slightly later during life, young animals need to forage for the same resources and escape the same predators as adults do, and this despite their small size (Herrel \& Gibb, 2006; Young \& Shapiro, 2018). In this context it is of interest to investigate the link between limb morphology and the associated grasping performance as this may provide insights into the behaviors used throughout ontogeny. Indeed, given the importance of grasping in the everyday life of young primates, selection may lead to strong grasping performance despite an immature neuromusculoskeletal system (Carrier, 1996; Young, 2005; Herrel \& Gibb, 2006; Lawler, 2006; Russo \& Young, 2011; Druelle, Aerts \& Berillon, 2016; Young \& Heard-Booth, 2016; Patel et al., 2018). Such ontogenetic studies on grasping are not numerous, but the existing ones have revealed specific features including a greater mechanical advantage, greater bone robusticity and larger bone extremities with relatively longer digits in infants compared to adults in strepsirrhine (Poindexter \& Nekaris, 2017) and haplorhine primates (Russo \& Young, 2011; Young \& Heard-Booth, 2016; Druelle et al., 2017; Patel et al., 2018), suggesting selection on grasping performance. 
Some studies have also investigated this topic by comparing arboreal versus terrestrial rodents and marsupials (Ishiwaka \& Mori, 1999; Shapiro, Young \& VandeBerg, 2014).

The objective of this study was to investigate the ontogeny of grasping performance, behavior and morphology in the gray mouse lemur, Microcebus murinus. This small arboreal primate belongs to the Cheirogaleidae (Petter, 2010). This species is a small-sized, omnivorous and nocturnal primate, exploiting a narrow branch niche likely requiring strong grasping (Martin, 1972; Charles-Dominique, 1977; Thomas et al., 2015b). Moreover, mouse lemurs are fast-growing animals, with independent exploration of their environment starting at the age of 2 weeks, a weaning at 3 months and an adult morphology at the age of 6 months (Colas, 1999). This makes this species ideally suited for ontogenetic studies. In this study, we quantified behavioral (manual food grasping strategies when confronted with mobile prey), morphological (segment dimensions of hind- and forelimbs) and performance traits (hand and foot pull strength) of mouse lemurs during the first 6 months of their life. We first predict that (A) juveniles extremities (i.e. hind- and forelimbs) will develop quickly, being relatively longer than in adults. We also predict (B) juveniles extremities to have strong grasping abilities, with hand and foot maximal pull strengths being relatively high compared to adults. We further expect thanks to our ontogenetic approach (C) to correlate these high grasping performances in juveniles to their specific morphological traits (i.e. relative longer segments) and expect (D) grasping behavior to vary according to morphological and performance traits. This fast development of grasping abilities would highlight the importance of this function directly after birth, making juveniles adapted to the foraging and locomotion constraints of their environment.

\section{Materials and methods}

\section{Subjects and housing}

All individuals (Microcebus murinus) were born and raised in the captive colony of the UMR 7179 (CNRS/MNHN) of the Muséum National d'Histoire Naturelle (Brunoy, France, Agreement \# 962773). These animals are descendants from wild individuals caught along the southwestern coast of Madagascar 50 years ago. Until 3 months, juveniles are housed with their siblings and their mother in $66 \times 50 \times 60 \mathrm{~cm}$ enclosures. After weaning, young mouse lemurs are placed in larger cages $(167 \times 60 \times 70 \mathrm{~cm})$ with two to seven individuals. All cages are enriched with branches and wooden nest boxes. Temperature and humidity are maintained around $25^{\circ} \mathrm{C}$ and $40 \%$, respectively. The photoperiod is controlled with a 14:10-h Light:Dark cycle for the summer-like season and 10:14 for the winter-like season. Animals are fed thrice weekly with fruit (pieces of apple, banana and oranges), and a special preparation made of condensed milk, Blédine (cereals \& milk mixture), egg yolk and gingerbread. Water is provided ad libitum.

In total, we studied 43 individuals: 14 individuals of 1 month and a half (seven males, seven females); 16 individuals of 3 months (seven males, nine females) and 13 individuals of six months (five males, eight females). Our total sample contained 24 females and 19 males. Animals are identified by an ear tag. The ethics committee of the Museum National d'Histoire Naturelle approved all measurements. The research adhered to the legal requirements of the European Union.

\section{Morphometrics}

For the purposes of this study we took the following external measurements: ulna, tibia, metatarsus and the following head dimensions: head length, head width and head height (Thomas et al., 2015a,b). The measurements were performed using a digital caliper $(0.01 \mathrm{~mm}$; Mitutoyo \& Kanagawa, Japan; Thomas et al., 2015a,b). Each measurement was repeated three times. We kept the median value for the data analysis. The length of metacarpals would be a very relevant parameter to consider. However, this measurement being not repeatable using external measurements, we decided to exclude this parameter from our analysis. Body mass was measured using a digital scale (Ohaus Scout Pro; Ohaus, Nänikon, Switzerland). One experimenter (GBA) performed the measurements while another held the animal.

\section{Performance measurements}

Pull strength of hands and feet were measured using a force platform as previously described (Herrel et al., 2013; Thomas et al., 2015b). The device is composed of a small iron bar (diameter adapted to hand size of the studied organism) fixed on a piezoelectric force platform (Kistler squirrel force plate, \pm $0.1 \mathrm{~N}$; Winterthur, Switzerland). This platform is placed on a custom-designed metal base and connected to a charge amplifier (Kistler charge amplifier type 9865). Forces (N) are recorded at $1 \mathrm{kHz}$ during $60 \mathrm{~s}$ sessions. During one session, the animal repeatedly gripped a dowel with its hands or feet and was then pulled away horizontally from the dowel. Each animal participated in two sessions: one focusing on the hands and another on the feet. Results were analyzed with the Bioware software (Kistler). The maximal pull strength (hands and feet) of each animal was extracted from the three-dimensional force recording (=vector sum of $X, Y$ and $Z ; \quad F=$ $\left.\sqrt{x^{2}+y^{2}+z^{2}}\right)$.

\section{Grasping behavior}

A series of five experimental feeding sessions was carried out for each individual. For this behavioral test the animal was placed in a custom-designed box $(18 \times 8.5 \times 28 \mathrm{~cm})$ containing a horizontal substrate of $1.6 \mathrm{~cm}$ in diameter mimicking a branch that the mouse lemur is able to grasp (i.e. the feet and hands can be closed around it). At the beginning of each session, a food item attached to a thin transparent thread was inserted inside the box by the experimenter who moved it vertically. The hand surface area of the hand of a mouse lemur of 1 month and a half is approximately $1 \mathrm{~cm}^{2}$. Moreover, Reghem et al. (2011) showed in adults that for food items of $1 \mathrm{~cm}^{3}$ or larger, the grasping strategy no longer changes when increasing the size of the item further. Thus we used for all trials pieces of banana of about $1 \mathrm{~cm}^{3}$. For each age group, 
behavioral tests were performed within 2 weeks after the morphometric and performance measurements due to the rapid growth of $M$. murinus. Consequently we had to reduce the sample to 10 individuals per developmental stage for the behavioral experiments. The front of the test box was made of transparent plexiglass allowing each trial to be filmed using a camera (SONY Handycam DCR-SR75). Video analyses were conducted with the software VLC media player. During each feeding session we recorded the prehension strategy displayed to grasp the moving food item: one hand, both hands, mouth alone and both mouth and hand(s). As the diameter and the slope of the substrate influence the grasping strategy (Toussaint et al., 2013, 2015), only those grasps realized when the animal was on the branch were recorded.

\section{Data analysis}

We ran linear models in order to explore relations between limb morphology and grasping performance, and between grasping behavior and grasping performance and morphology. We also tested effects of age and sex as predictors of morphology and performance. For each model, we calculated the variance-inflation factors (VIF) in order to test for collinearity. We kept variables having a VIF lower than five and ensured that the mean of the VIFs was lower than two (Chatterjee, Hadi \& Price, 2000; De Bourmont, 2012). We then ran Anovas to test the statistical significance of the model. Model selection was based on the Akaike Information Criterion (AIC). We checked normality and homoscedasticity by performing both Shapiro-Wilk Normality and BreuschPagan tests. In addition to the age we used a qualitative variable describing the three developmental stages (1 month and half, 3 months, 6 months), allowing the use of pairwise $t$-tests and the non-parametric Kruskal-Wallis rank sum test. We used the following RStudio packages: FactoMineR, car, MASS, readxl, lmtest, nlme and lme4. All statistics were performed using a $\alpha$-level of 0.05 .

We scaled morphological traits to body mass in order to compare limb proportions throughout development (segment lengths are multiplied by (body mass) ${ }^{1 / 3}$; Hof, 1996). Morphological data were also square root-transformed before analyses to meet assumptions of normality and homoscedasticity of residuals. We then ran General Linear Models with morphometric variables (forearm, tibia and metatarsus lengths and head dimensions) to test for differences between animals of different age classes and sexes. We also calculated a metatarsus on tibia ratio. As this variable did not follow a normal distribution we performed a non-parametric Kruskal-Wallis rank sum test to compare it between the different developmental stages (qualitative variable).

Performance traits were scaled to body mass (performance/9.81(body mass); Hof, 1996) and log10-transformed before analyses. We ran a multiple regression to test for associations between performance and morphology. We also ran linear models with age and sex as fixed variables to investigate possible differences in grasping performance across ontogeny. In parallel, we ran a Kruskal-Wallis test to compare performance of the different development stages.
The proportion of grip types was calculated for each individual. As the variables did not follow a normal distribution, we performed a Kruskal-Wallis rank sum test to compare for each grasping behavior across the different developmental stages.

\section{Results}

\section{Morphology according to age}

Linear models detected that the relative tibia and metatarsus lengths decreased significantly with age (metatarsus: $F_{1,41}=$ 42.24; $P<0.001$; tibia: $F_{1,41}=4.609 ; P=0.037$; Fig. 1 ). Neither sex nor age were significant predictors of ulna length. A Kruskal-Wallis rank sum test revealed a significant difference of metatarsal to tibia ratio between development stages (KruskalWallis chi-squared $=16.6 ; P<0.001$ ), (Fig. 2). The means of the raw and scaled data are provided in Table 2.

\section{Performance according to age}

Linear models did not detect a significant effect of age or sex on performance scaled to body mass. However, when performing a Kruskal-Wallis rank sum test with the developmental stages as a qualitative predictive variable, we found that at least two stages were significantly different for both relative hand and foot pull strength (Feet: Kruskal-Wallis chisquared $=12.75 ; \quad P=0.0017 ; \quad$ Hands: Kruskal-Wallis chisquared $=29.31 ; \quad P<0.001)$. Consequently, we compared developmental stages two by two and found no difference between 1-month-and-half-old and 6-month-old individuals, but theses stages were both significantly different from the 3-month-old individuals (Table 1 and Fig. 3). Means of the raw and scaled data are provided in Table 2.

\section{Morphometric predictors of performance}

Linear models detected first that the relative foot pull strength increased significantly with the relative tibia length $\left(F_{2,40}=15.38 ; P<0.001\right)$, the model also kept the head width

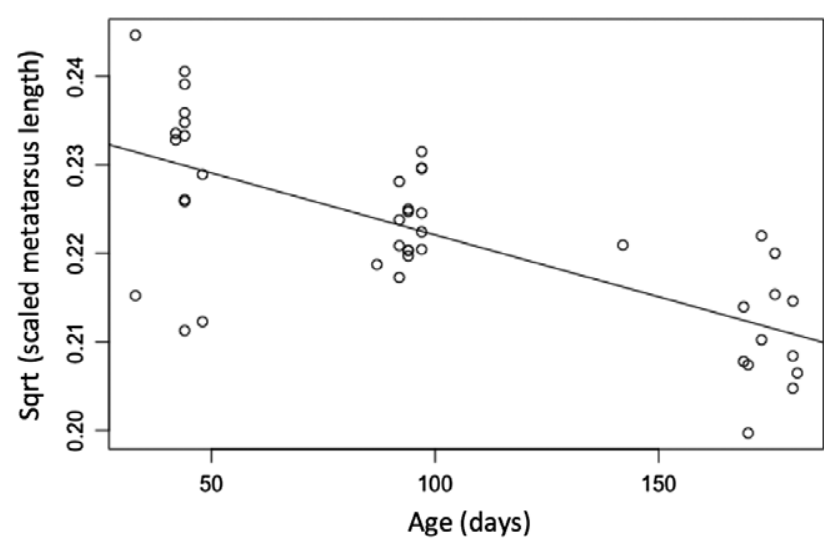

Figure 1 Plot of the relation between the length of metatarsus scaled to body mass and age in Microcebus murinus. 


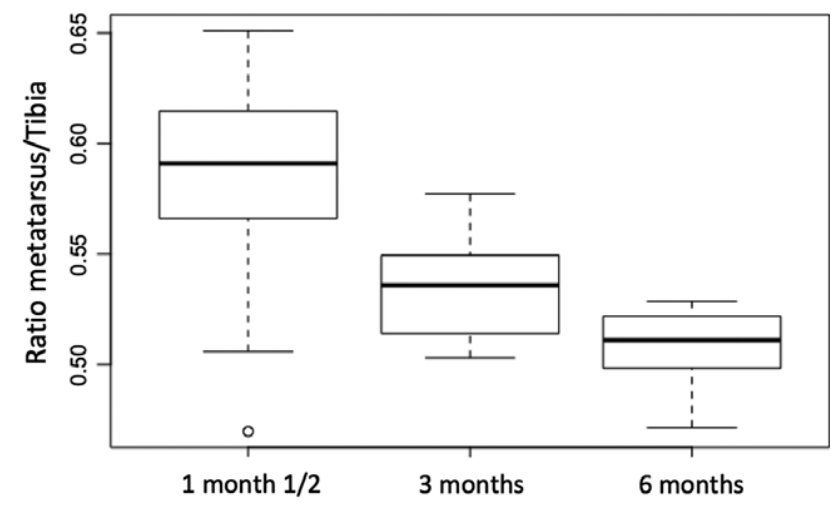

Figure 2 Boxplot of the ratio of the lengths of metatarsus relative to tibia at three different developmental stages in Microcebus murinus.

with a trend $\left(F_{2,40}=3.33 ; P=0.07\right)$. The relative hand pull strength increased significantly with the relative ulna length $\left(F_{2,40}=11.56 ; P=0.0015\right)$, and the model kept the relative metatarsus length as a non-significant element $\left(F_{2,40}=2.20\right.$; $P=0.146)$, (Fig. 4).

\section{Predictors of grasping behavior}

Kruskal-Wallis rank sum tests, with the developmental stages as a qualitative predictive variable, detected no difference in grasping behavior across the development. In fact, mouse lemurs displayed bimanual grasps in the majority of the sessions $(85.3 \%)$, the mouth alone strategy was never used. This low variability in food grasping strategies did not allow us to highlight correlations between different grasping behaviors and different performance or morphological traits.

\section{Discussion}

Our general hypothesis was that behavioral and performance parameters would vary according to developmental stages in connection with morphological changes. Our results assessed three of our four predictions.

Our first prediction (A) pertained to the quick development of grasping extremities and was validated: younger mouse lemurs had relative longer hindlimb segments than older

Table 1 Results of $t$-tests run to compare pull strength (scaled to body mass) between the three developmental stages in Microcebus murinus

\begin{tabular}{|c|c|c|c|c|c|c|}
\hline \multirow[b]{2}{*}{$t$ test } & \multicolumn{3}{|c|}{ Hand pull strength } & \multicolumn{3}{|c|}{ Foot pull strength } \\
\hline & Means & $t$ & $P$ & Means & $t$ & $P$ \\
\hline$\overline{(a)-(b)}$ & $\mathrm{ma}<\mathrm{mb}$ & -2.86 & 0.0082 & $\mathrm{ma}<\mathrm{mb}$ & -3.56 & 0.0013 \\
\hline (b)-(c) & $m b>m c$ & 3.65 & 0.0011 & $m b>m c$ & 3.60 & 0.0013 \\
\hline (c)-(a) & $\mathrm{mc} \sim \mathrm{ma}$ & 0.40 & 0.69 & $\mathrm{mc} \sim \mathrm{ma}$ & -0.24 & 0.81 \\
\hline
\end{tabular}

(a): 1 month and half, (b): 3 months, (c) 6 months.

Means of hand pull strength: $\mathrm{ma}=2.44, \mathrm{mb}=2.70, \mathrm{mc}=2.40$.

For the feet: $\mathrm{ma}=1.54, \mathrm{mb}=1.93, \mathrm{mc}=1.56$. individuals. Indeed, they had relatively longer metatarsus and tibia lengths relative to body mass. These results agree with previous studies on limb segment size and bone robusticity in another small strepsirhine, the Javan slow lorises (Nycticebus javanicus; Poindexter \& Nekaris, 2017), but also with results for several haplorhines including young baboons (Papio anubis), capuchin monkeys (Sapajus apella, Cebus albifrons), chimpanzees (Pan troglodytes) and rhesus monkeys (Macaca mulatta) (Young \& Heard-Booth, 2016; Druelle et al., 2017; Patel et al., 2018). In marsupials (Shapiro et al., 2014), morphology was not influenced by relative age but extremities were longer in an arboreal (Petaurus breviceps) species than in a terrestrial (Monodelphis domestica) one. Regarding the forelimb, we did not find differences in the length of the ulna. We focused on ulna for the forelimb because it can easily be measured in vivo and because previous studies demonstrated that ulna length was correlated with pull strength (Thomas et al., 2015b). It would, however, be of interest to conduct further studies on the forelimb anatomy specifically comparing hands segment. Although our external morphological measurement protocol did not allow us to study the development of the metacarpals, it is likely a relevant parameter. Indeed, hands and feet are made of a lot of different segments that all can have their own growth allometries such as digits and metapodia, which contribute strongly to the grasping architecture of hands and feet (Napier, 1961). Using radiographs, Young \& Heard-Booth (2016) showed variations in the proportions of hand and foot bones during development in capuchins. By analyzing growth curves of different limb segments they demonstrated that the metapodials grow at a faster rate than the corresponding phalanges. Such growth allometries resulted in juveniles having longer fingers and toes for their size.

Our prediction (B) related to the predicted relative high grasping performance in juveniles and was also validated. Associated with the specific morphologic features discussed above, we found relative high grasping performance in juveniles. Relative to their body mass, 1-month-old individuals displayed a grasping performance that was equivalent to that of 6-month-old individuals. We were unable to demonstrate an effect of age during growth. However, when comparing developmental stages two by two we detected that 1-month-andhalf-old and 6-month-old individuals were weaker than 3month-old individuals. This can be possibly explained by the fact that data were scaled relative to body mass. Thus, relative to body mass the grasping performance of young mouse lemurs is the highest at 3 months and relatively decreases after that because of significant mass gain. It is likely, however, that young mouse lemurs do not possess the same muscle mass and strength as adults do. In neonate rhesus macaques (Macaca mulatta), muscle mass makes up only $24 \%$ of the total body mass, whereas it accounts for $43 \%$ of total body mass in adults (Grand, 1977). Thus, the morphological features of juveniles (i.e. longer and more robust extremities) may be involved in compensatory mechanisms allowing them to grasp strongly despite neuromuscular immaturity (Carrier, 1996; Young, 2005; Lawler, 2006; Russo \& Young, 2011; Young \& Heard-Booth, 2016). Indeed, in this study we highlighted direct relationships between tibia length and foot grasping 

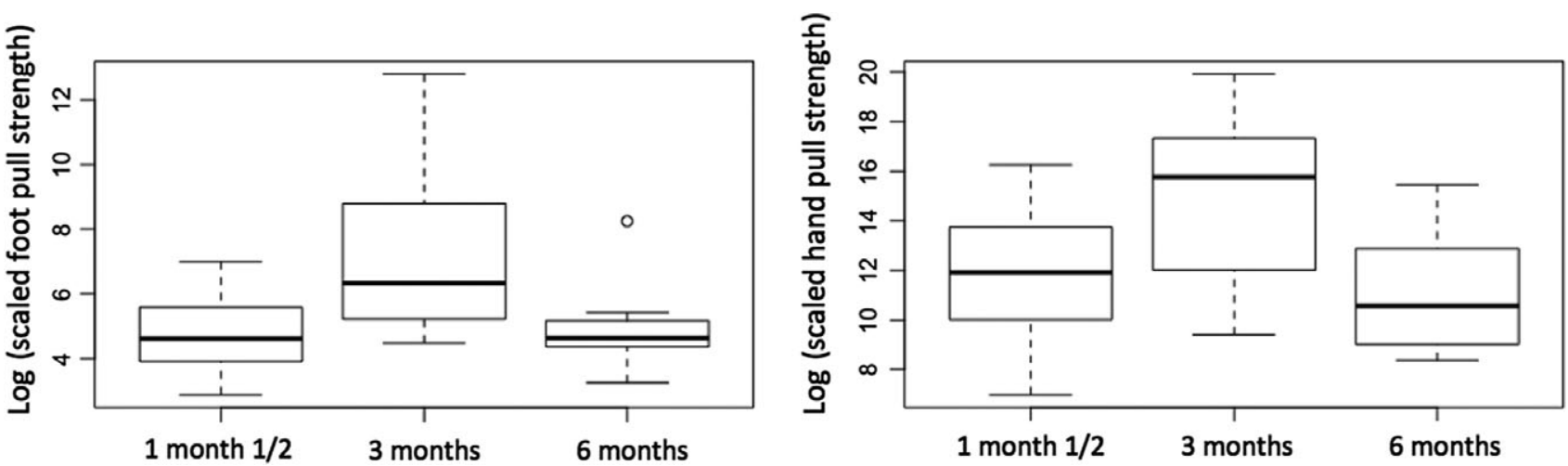

Figure 3 Boxplot of the foot and hand pull strengths at three different developmental stages in Microcebus murinus.

Table 2 Summary detailing differences between developmental stages in morphology and pull strength

\begin{tabular}{|c|c|c|c|c|}
\hline & & $\begin{array}{l}1.5 \text { months } \\
N=14\end{array}$ & $\begin{array}{l}3 \text { months } \\
N=16\end{array}$ & $\begin{array}{l}6 \text { months } \\
N=13\end{array}$ \\
\hline \multirow[t]{6}{*}{ Raw data } & Metatarsus (mm) & $18.14 \pm 1.25$ & $19.63 \pm 0.96$ & $19.77 \pm 1.03$ \\
\hline & Tibia $(\mathrm{mm})$ & $31.255 \pm 1.45$ & $36.85 \pm 1.27$ & $38.83 \pm 1.58$ \\
\hline & Ulna $(\mathrm{mm})$ & $21.15 \pm 1.08$ & $25.87 \pm 1.58$ & $27.72 \pm 1.02$ \\
\hline & Hand pull strength (N) & $4.64 \pm 0.82$ & $9.08 \pm 2.22$ & $9.62 \pm 2.42$ \\
\hline & Foot pull strength (N) & $1.91 \pm 0.44$ & $4.24 \pm 1.26$ & $4.16 \pm 1.08$ \\
\hline & Body mass (g) & $41.21 \pm 6.3$ & $61.00 \pm 8.32$ & $87.38 \pm 16.86$ \\
\hline \multirow[t]{5}{*}{ Scaled data } & Metatarsus & $0.052 \pm 0.0047$ & $0.049 \pm 0.0019$ & $0.044 \pm 0.0028$ \\
\hline & Tibia & $0.0907 \pm 0.0031$ & $0.093 \pm 0.0031$ & $0.088 \pm 0.0042$ \\
\hline & Ulna & $0.061 \pm 0.0039$ & $0.065 \pm 0.0028$ & $0.062 \pm 0.0029$ \\
\hline & Hand pull strength & $11.82 \pm 2.95$ & $15.17 \pm 3.22$ & $11.27 \pm 2.42$ \\
\hline & Foot pull strength & $4.82 \pm 1.24$ & $7.23 \pm 2.54$ & $4.88 \pm 1.16$ \\
\hline
\end{tabular}

Table entries are means \pm SD.

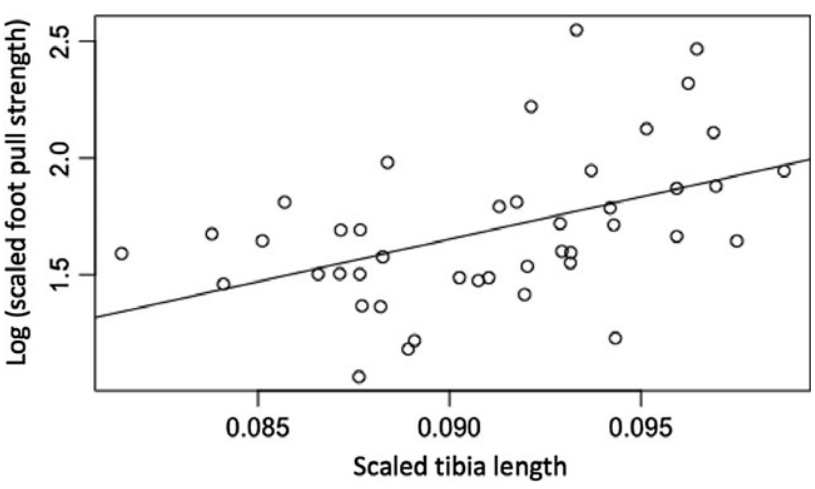

Figure 4 Plot of the linear relation between the foot pull strength and the length of the tibia, both scaled to body mass, in Microcebus murinus.

performance, which confirmed our prediction C. Furthermore, recent studies established a link between relatively large extremities and increased grasping ability in young primates (Young \& Heard-Booth, 2016; Druelle et al., 2017). Moreover, changes in the proportions of the limb segments were associated to a decrease in suspensory behaviors throughout the development in Olive Baboons (Druelle et al., 2017). Moreover, results on the ontogeny of prehensile tails show similarities with the hind- and forelimbs as described here. Specifically, younger individuals display greater bone robustness of the caudal vertebrae involved in grasping compared to adults. This is associated with greater tail strength and promotes tail-suspension behavior (Russo \& Young, 2011). However, to better understand the relations between morphology and performance we need further studies investigating the patterns of muscle mass distribution during the development. Also understanding the tendon development in the extremities would be important as their role in the early development of grasping abilities may be significant. We did not find any effect of sex on grasping performance during development, which matches previously published data for M. murinus (Thomas et al., 2015b).

Our results did not confirm our prediction D: grasping behavior did not vary during development according to variations in morphological and performance traits. Juveniles used adult behaviors very early on; they used bimanual grasps in the large majority of the sessions (85.3\%), the mouth alone being never used. Toussaint et al. (2013) also identified the bimanual grasp as the preferred strategy used to capture mobile objects in adults. In contrast, in the case of static food items 
the mouth is used in the majority of the cases. The use of a prehensile organ disconnected from a function in body support may optimize prey capture by avoiding whole body displacement which could decrease balance and attract predators (Toussaint et al., 2013). In this study, we demonstrated that young mouse lemurs (1 month old) already possess the whole grasping repertoire observed in older individuals. The performance of this adult grasping behavior may be explained by the strong grasping performance of juveniles made possible because of specific morphologic features. Indeed, strong prehensile feet may provide a sufficient balance when holding on a branch while allowing the use of both hands during foraging. In addition, other studies have highlighted the link between morphology, performance and locomotor behavior, for example in gorillas (Gorilla beringei) and chimpanzees (Pan troglodytes) where the relative strength of hindlimb and forelimb bones tracks changes in locomotion during growth (Ruff et al., 2013; Sarringhaus, Maclatchy \& Mitani, 2016; Young \& Shapiro, 2018). Furthermore, bimanual grasping is a bimanual symmetric grasping that requires motor coordination. Consequently, this suggests that the development of motor coordination in mouse lemurs occurs early during ontogeny.

Finally, our results suggest that the development of the limbs and grasping in primates is tightly associated with the arboreal milieu. It has been observed that only 2 weeks after birth, mouse lemurs begin to explore their environment and already use narrow substrates requiring a strong grip to maintain balance (Colas, 1999). The relatively large and robust extremities of juveniles provide stability during arboreal locomotion with a reduced risk of falling and subsequent skeletal injury (Young \& Shapiro, 2018). Byron et al. (2015) showed that mice raised in enclosures with fine branch arboreal substrates displayed more robust foot bones than ones raised on the ground and that did not need to use their hallux to grasp substrates. Early acquisition of adult locomotor and feeding behaviors associated with fast limb development, as we observed in this study on mouse lemurs, has been also observed in Javan slow lorises (Nycticebus javanicus) that utilize the same fine terminal branches. Also in small harvest mice, able to climb on long vertical grasses before the end of the short lactation period of 15 days (Ishiwaka \& Mori, 1999; Poindexter \& Nekaris, 2017) a similar pattern is observed. This fast acquisition of grasping ability emphasizes its crucial importance involved in both locomotion (to hold either on branches or the mother) and foraging. Indeed, Lawler (2006) showed a direct positive relationship between foot length and survivorship to maturity in sifakas. Interestingly, juvenile mouse lemurs had relatively large tibia and metatarsi but an ulna length similar to that of older individuals. Thus, it seems that there is a stronger constraint on the grasping ability of the hindlimb than for the forelimb early in life. Capuchin monkeys (Cebus albifrons \& Sapajus apella, Young \& Heard-Booth, 2016) showed a stronger ontogenetic decline in hallucial phalangeal indices than in manual phalangeal indices. Moreover, throughout the development of baboons (Papio anubis), the pedal postaxial digit phalangeal index is correlated with the time spent in arboreal locomotion behaviors (i.e. suspension, climbing, clinging), whereas no correlations were observed with hand proportions (Druelle et al., 2017). Patel et al. (2015) compared pedal and manual grasping control in red ruffed lemurs (Varecia rubra) walking quadrupedally on an arboreal substrate. Their EMG recordings showed a higher and longer activation of toe flexors than of finger flexors. The authors suggested therefore that red ruffed lemurs relied less on forelimb than on hindlimb grasps during quadrupedal locomotion. This may suggest different functional roles of the hands and feet. Consequently, they may have evolved in different selective contexts. Although both hands and feet are used during locomotion on narrow branches the feet provide the body balance by holding on strongly to the branch, liberating the forelimbs for other functions (Cartmill, 1985). This division of function may suggest a more substantial role of the feet in the primate locomotor development, at least for arboreal species. Grasping hands, on the other hand, may have evolved under foraging constraints, allowing the grasping and manipulation of resources in the arboreal fine terminal branch milieu (Rolian, Lieberman \& Hallgrímsson, 2010; Young \& HeardBooth, 2016; Druelle et al., 2017). Studies comparing forelimb and hindlimb development are a few but the elements they brought out have a real importance to better identify the ecological constraints that lead to the grasping abilities of primate hands and feet. We thus need further studies investigating the development of manual versus pedal grasping abilities in a wide range of arboreal species.

To conclude, young mouse lemurs have relatively large limb segments that facilitate strong grasping and high levels of stability despite an immature neuromuscular system. The fast acquisition of grasping ability highlights the importance of this function directly after birth in this group. As we did not observe a diversity of food grasping strategies throughout development no relations between behavioral strategies and morphology were present. However, we expect a higher variability in grasping strategies displayed during locomotion. Further ontogenetic studies investigating grasping strategies during locomotion on different types of substrates may highlight further relations between anatomy, performance and behavior.

\section{Acknowledgments}

We thank Martine Perret for logistic support, and the animal keepers Sandrine Gondor and Laurianne Dezaire. We thank MNHN and the DEFI AUTON 'Mission pour l'interdisciplinarité' (CNRS) for the funding and the Center for Research and Interdisciplinarity (CRI, Paris) for financial aid. Finally, we thank the two anonymous reviewers for their relevant comments, which greatly improved our paper.

\section{References}

Byron, C.D., Herrel, A., Pauwels, E., De Muynck, A. \& Patel, B.A. (2015). Mouse hallucal metatarsal cross-sectional geometry in a simulated fine branch niche: hallucal metatarsal morphology. J. Morphol. 276, 759-765.

Carrier, D. (1996). Ontogenetic limits on locomotor performance. Physiol. Zool. 69, 467-488. 
Cartmill, M. (1985). Climbing. In Functional vertebrate morphology: 73-88. Hildebrand, M., Bramble, D.M., Liem, K.F. \& Wake, D.B. (Eds). Cambridge: Harvard University Press.

Charles-Dominique, P. (1977). Ecology and behavior of nocturnal primates. New York: Columbia University Press.

Chatterjee, S., Hadi, A.S. \& Price, B. (2000). Regression analysis by example. New York: John Wiley \& Sons.

Colas, S. (1999). Investissement maternel, physiologique et comportemental chez un primate, M. murinus (Unpublished doctoral dissertation). Paris 13 University, Paris.

De Bourmont, M. (2012). La résolution d'un problème de multicolinéarité au sein des études portant sur les déterminants d'une publication volontaire d'informations : proposition d'un algorithme de décision simplifié basé sur les indicateurs de Belsley, Kuh et Welsch (1980). Grenoble, France: Comptabilités et innovation. May,. pp.cd-rom, $<$ hal00691156>.

Doran, D.M. (1992). The ontogeny of chimpanzee and pygmy chimpanzee locomotor behavior: a case study of paedomorphism and its behavioral correlates. J. Hum. Evol. 23, 139-157.

Doran, D.M. (1997). Ontogeny of locomotion in mountain gorillas and chimpanzees. J. Hum. Evol. 32, 323-344.

Druelle, F., Aerts, P. \& Berillon, G. (2016). Effect of body mass distribution on the ontogeny of positional behaviors in nonhuman primates: longitudinal follow-up of infant captive olive baboons (Papio Anubis): body mass distribution and positional repertoire. Am. J. Primatol. 78, 1201-1221.

Druelle, F., Young, J. \& Berillon, G. (2017). Behavioral implications of ontogenetic changes in intrinsic hand and foot proportions in olive baboons (Papio Anubis). Am. J. Phys. Anthropol. 165, 65-76.

Grand, T.I. (1977). Body weight: its relation to tissue composition, segment distribution, and motor function. II. Development of Macaca mulatta. Am. J. Phys. Anthropol. 47, 241-248.

Herrel, A. \& Gibb, A.C. (2006). Ontogeny of performance in vertebrates. Physiol. Biochem. Zool. 79, 1-6.

Herrel, A., Tolley, K.A., Measey, G.J., da Silva, J.M., Potgieter, D.F., Boller, E., Boistel, R. \& Vanhooydonck, B. (2013). Slow but tenacious: an analysis of running and gripping performance in chameleons. J. Exp. Biol. 216, 1025-1030.

Hof, L. (1996). Scaling gait data to body size. Gait Posture. 4, 222-223.

Ishiwaka, R. \& Mori, T. (1999). Early development of climbing skills in harvest mice. Anim. Behav. 58, 203-209.

Lawler, R.R. (2006). Sifaka positional behavior: ontogenetic and quantitative genetic approaches. Am. J. Phys. Anthropol. 131, 261-271.

Martin, R.D. (1972). Adaptive radiation and behavior of the Malagasy lemurs. Philos. Trans. R. Soc. Lond. B. Biol. Sci. 264, 295-352.

Nakamichi, M. \& Yamada, K. (2009). Distribution of dorsal carriage among simians. Primates 50, 153-168.
Napier, J.R. (1956). The prehensile movements of the human hand. J. Bone Joint Surg. Br. 38B, 902-913.

Napier, J.R. (1961). Prehensility and opposability in the hands of primates. Symp. Zool. Soc. Lond. 5, 115-132.

Patel, B.A., Wallace, I.J., Boyer, D.M., Granatosky, M.C., Larson, S.G. \& Stern, J.T. (2015). Distinct functional roles of primate grasping hands and feet during arboreal quadrupedal locomotion. J. Hum. Evol. 88, 79-84.

Patel, B.A., Organ, J.M., Jashashvili, T., Bui, S.H. \& Dunsworth, H.M. (2018). Ontogeny of hallucal metatarsal rigidity and shape in the rhesus monkey (Macaca Mulatta) and chimpanzee (Pan Troglodytes). J. Anat. 232, 39-53.

Peckre, L., Fabre, A.C., Wall, C.E., Brewer, D., Ehmke, E., Haring, D., Shaw, E., Welser, K. \& Pouydebat, E. (2016). Holding-on: co-evolution between infant carrying and grasping behaviour in strepsirrhines. Sci. Rep. 6, 37729.

Petter, J.J. (2010). Primates: 256. Paris : Nathan (Eds.).

Poindexter, S.A. \& Nekaris, K.A.I. (2017). Vertical clingers and gougers: rapid acquisition of adult limb proportions facilitates feeding behaviors in young Javan slow lorises (Nycticebus Javanicus). Mamm. Biol. 87, 40-49.

Pouydebat, E., Gorce, P. \& Bels, V. (2009). Biomechanical study of grasping according to the volume of the object: human versus non-human primates. J. Biomech. 42, 266-272.

Reghem, E., Tia, B., Bels, V. \& Pouydebat, E. (2011). Food prehension and manipulation in Microcebus murinus (Prosimii, Cheirogaleidae). Folia Primatol. 82, 177-188.

Rolian, C., Lieberman, D.E. \& Hallgrímsson, B. (2010). The coevolution of human hands and feet: coevolution of human hands and feet. Evolution 64, 1558-1568.

Ruff, C.B., Burgess, M.L., Bromage, T.G., Mudakikwa, A. \& McFarlin, S.C. (2013). Ontogenetic changes in limb bone structural proportions in mountain gorillas (Gorilla beringei beringei). J. Hum. Evol. 65, 693-703.

Russo, G.A. \& Young, J.W. (2011). Tail growth tracks the ontogeny of prehensile tail use in capuchin monkeys (Cebus Albifrons and C. Apella). Am. J. Phys. Anthropol. 146, 465473.

Sarringhaus, L.A., MacLatchy, L.M. \& Mitani, J.C. (2014). Locomotor and postural development of wild chimpanzees. J. Hum. Evol. 66, 29-38.

Sarringhaus, L.A., Maclatchy, L.M. \& Mitani, J.C. (2016). Long bone cross- sectional properties reflect changes in locomotor behavior in developing chimpanzees. Am. J. Phys. Anthropol. 160, 16-29.

Shapiro, L.J., Young, J.W. \& VandeBerg, J.L. (2014). Body size and the small branch niche: using marsupial ontogeny to model primate locomotor evolution. J. Hum. Evol. 68, 14-31.

Sustaita, D., Pouydebat, E., Abdala, V., Manzano, A. \& Herrel, A. (2013). Getting a grip on tetrapod grasping: Form, function and evolution. Biol. Rev. 88, 380-405.

Thomas, P., Pouydebat, E., Hardy, I., Aujard, F., Ross, C.F. \& Herrel, A. (2015a). Sexual dimorphism in bite force in the grey mouse lemur: lemur bite force sexual dimorphism. J. Zool. 296, 133-138. 
Thomas, P., Pouydebat, E., Le Brazidec, M., Aujard, F. \& Herrel, A. (2015b). Determinants of pull strength in captive grey mouse lemurs. J. Zool. 298, 77-81.

Toussaint, S., Reghem, E., Chotard, H., Herrel, A., Ross, C.F. \& Pouydebat, E. (2013). Food acquisition on arboreal substrates by the grey mouse lemur: implication for Primate grasping evolution: hand use during food acquisition in Microcebus Murinus. J. Zool. 291, 235-242.

Toussaint, S., Herrel, A., Ross, C.F., Aujard, F. \& Pouydebat, E. (2015). The use of substrate diameter and orientation in the context of food type in the mouse lemur, Microcebus murinus: implications for the origins of grasping in primates. Int. J. Primatol. 36, 583-604.
Völter, C.J., Rossano, F. \& Call, J. (2015). From exploitation to cooperation: social tool use in Orang-Utan mother-offspring dyads. Anim. Behav. 100, 126-134.

Young, J.W. (2005). Ontogeny of muscle mechanical advantage in capuchin monkeys (Cebus Albifrons and Cebus Apella). J. Zool. 267, 351.

Young, J.W. \& Heard-Booth, A.N. (2016). Grasping primate development: ontogeny of intrinsic hand and foot proportions in capuchin monkeys (Cebus albifrons and Sapajus apella). Am. J. Phys. Anthropol. 161, 104-115.

Young, J.W. \& Shapiro, L.J. (2018). Developments in development: what have we learned from primate locomotor ontogeny? Am. J. Phys. Anthropol. 165, 37-71. 